\title{
The Geopolitical Environment in Namibia: Business Challenges and Opportunities
}

\author{
Ravinder Rena \\ Department of Economics, Faculty of Economic and Management Sciences (EMS), \\ University of the Western Cape, Private Bag: X17, Robert Sobukwe Road, \\ Bellville 7535 South Africa \\ E-mail:rrena@uwc.ac.za; drravinderrena@gmail.com
}

KEYWORDS Geopolitics. Population Grown. Migration. Namibia. Human Development

\begin{abstract}
Geopolitics and business development is a buzz word. There is a serious link between population growth and the environment. This is basically found somewhere between the view that population growth is solely responsible for all environmental ills and the view that more people means the development of new technologies to overcome any environmental problems. An attempt has been made in this article to discuss the geopolitical environment in Namibia and provides a comprehensive picture of the country's, economy, polity, education and health situation in the country. It also highlights the environment and migration issues in general and how that affects a developing country like Namibia. It further argues that action is required by a broad group of policy makers in Namibia who can take important policy intervention measures that can ameliorate the current business landscape of the country.
\end{abstract}

\section{INTRODUCTION AND BACKGROUND}

The link between population growth and the environment is found somewhere between the view that population growth is solely responsible for all environmental ills and the view that more people means the development of new technologies to overcome any environmental problems. Most environmentalists agree that population growth is only one of several interacting factors that place pressure on the environment. High levels of consumption and industrialization, inequality in wealth and land distribution, inappropriate government policies, poverty, and inefficient technologies all contribute to environmental degradation. In fact, population may not be a root cause in environmental decline, but rather just one factor among many that exacerbate or multiply the negative effects of other social, economic, and political factors. ${ }^{1}$

Much of the world's population live in poor countries already strained by food insecurity, inadequate sanitation, water supplies and housing, and an inability to meet the basic needs of the current population. These same countries are also among the fastest growing places in the world. A large proportion of these populations are supported through subsistence agriculture. As populations grow, competition for fertile land and the use of limited resources increase. The people living in these countries are also moving toward a greater standard of living, perhaps matching the lifestyles of the more developed countries whose current consumption patterns and resource use are not necessarily sustainable. $^{2}$

Further, a growing, urbanising global population over the next 50 years will create demand for more food, energy and water. Many of the modern 'megacities' are located in coastal areas or river deltas, which are vulnerable to rising water levels. Changes to our climate may cause degradation of agricultural land, desertification and increased levels of water and food scarcity. For some, this may threaten to create a 'perfect storm' of global events. Yet, until now, the connections between economics, demography, environment and migration have been far from certain, still less the consequences for public policy.

The number of international migrants has grown in recent years, to approximately $210 \mathrm{mil}-$ lion in 2010. It is clear that international migration is a significant phenomenon. It is often a life changing event for migrants themselves since it raises a number of questions in terms of governance and relations between states. It has particular implications when the impact of environmental change on migration drivers is concerned, as it is likely to lead to geopolitical policy challenges across the globe. Consequently, a range of major forces are set to cause profound changes in natural and human environ- 
ments across the world over the next 50 years (Politzer 2008; UNDP 2009). Besides climate change, include the growth of mega-cities, land degradation and the profound consequences of an increasing global population which is consuming ever more natural resources.

Yet, according to figures compiled in the 2009 Human Development Report, international migration makes up only about one-fifth of total migration in the world, with the vast majority of movement, conservatively estimated at 740 million people, occurring within national boundaries (UNDP 2009). Poor people are often affected by migration, as they or a family member have moved, often to a nearby town or village or to another part of their country. Yet, poor people are in general very unlikely to have access to international migration, as the cost is prohibitive. Secondly, internal migration can often be over substantial distances, and have significant impacts. For example, migration from one Namibian province to another or one South African province to another can take place over hundreds of kilometres, and involve movement to a place with a different language, customs or set of rights and entitlements. In this sense, it arguably deserves attention alongside international migration as a significant issue for policy.

However, thirdly, and perhaps most important, there is some evidence to suggest that where global environmental change does act to raise levels of migration and displacement, the majority of additional migrants remain within their country of origin, owing to the prohibitive cost of international migration. Moreover, evidence also suggests that internal migration is taking people to places where they are more rather than less vulnerable to environmental change-related risk. A generally accepted definition, and the one that is used here, is that internal migration should involve the crossing of a regional, district or municipal boundary, the size and political significance of which will vary greatly in different countries, and involve a movement lasting at least 3 months. However, this definition draws attention to a key feature of migration, which is that migration is not necessarily permanent, but may involve multiple episodes of shortterm migration, otherwise known as 'circulation'. It should also be noted that internal migration is more likely within large countries (such as Russia, Canada, USA, Brazil, China Australia, India Nigeria), whereas international migration is more likely to affect the inhabitants of small countries (such as Jamaica, Luxembourg, Nauru, Solomon Islands, and Tuvalu).

Short time-span, repeated and often short distance moves are especially significant for poorer people, as well as for groups such as women and children, who are often excluded from migration analysis. It can form a critical part of the livelihood strategy of poor households in vulnerable areas, and in that sense is particularly relevant to adaptation to environmental change. In addition, circulation is also a developing area of policy interest in terms of managing social tensions and conflicts associated with migration influenced by environmental change. There is little evidence available to support the theoretical notion that environmentally induced conflict will cause migration, or that migration influenced by environmental change will cause conflict.

\section{Geopolitics -Concepts/Definitions}

In line with the 2009 Human Development Report, this report uses the term 'migrant' or 'migration' to refer to individuals who have changed their place of residence either 'by crossing an international border (international migration) or by moving within their country of origin to another region, district or municipality (internal migration). In turn, human mobility (or 'movement') is defined as 'the ability of individuals, families or groups of people to choose their place of residence', (UNDP 2009). People are normally considered to be 'migrants' if they remain outside their original place of residence for a period of at least 3 months.

Geopolitics refers broadly to the relationship between politics and territory whether on local or international scale. It comprises the practice of analysing, prescribing, forecasting, and the using of political power over a given territory. Specifically, it is a method of foreign policy analysis, which seeks to understand, explain and predict international political behaviour primarily in terms of geographical variables. Those geographical variables generally refer togeographic location of the country or countries in question, size of the countries involved, climate of the region the countries are in, topography of the region, demography, natural resources and technological development (Evans and Newnham 1998). Traditionally, the term has applied 
primarily to the impact of geography on politics, but its usage has evolved over the past century to encompass wider connotations.

Geopolitics traditionally indicates the links between political power and geographic space. In concrete terms, it is often seen as a body of thought examining strategic prescriptions based on the relative importance of land power and sea power in world history. The geopolitical tradition had some consistent concerns with regards to geopolitical correlates of power in world politics, the identification of international core areas, and the relationships between naval and terrestrial capabilities (Oyvind 1988).

Academically, the study of geopolitics involves the analysis of geography, history and social science with reference to spatial politics and patterns at various scales. It is multidisciplinary in its scope, and includes all aspects of the social sciences with particular emphasis on political geography, international relations, the territorial aspects of political science and international law. Also, the study of geopolitics includes the study of the ensemble of relations between the interests of international political actors, interests focused to an area, space, geographical element or ways, relations which create a geopolitical system (Vladimir 2006).

\section{Namibia Profile}

Namibia is located in the south-west of Africa bordering South Africa, Botswana, Zambia and Angola. It covers 824,000 square kilometres, but accommodates a small population of just 2 million people. Namibia is the driest country in sub- Saharan Africa, with an annual average rainfall of about 100 millimetres in the south, 400 millimetres in the central regions and around 600 millimetres $\mathrm{mm}$ in the northeast. The only perennial rivers form the borders with Angola and Zambia in the north and north-east, Botswana in the north-east and South Africa in the south. All rivers within the country are ephemeral and carry water during heavy rainfalls only. The Namib Desert - one of the oldest deserts on earth - stretches about 80 kilometres inland from the coast, while Namibia's eastern parts are characterized by the Kalahari Desert (RoN1990; NEPRU 1999; Kössler and Melber 2001).

It is a country with a turbulent past. The Namibian War of Independence, which lasted from 1966 to 1988 , was a guerrilla war, which the nationalist South-West Africa People's Organization (SWAPO) and others, fought against the apartheid government in South Africa. It was closely intertwined with the South African Border War. South Africa had administered what was then still known as South West Africa since it captured the German territory during World War I. In 1966, the United Nations General Assembly revoked South Africa's mandate to govern South-West African territory and declared that it was under direct UN administration. South Africa refused to recognize this resolution and continued to administer the territory de facto. On August 26, 1966, SWAPO guerilla forces launched an attack against the South African Defence Force at Omugulugwombashe. It was the first armed battle in the Namibian struggle for independence. The war ended with the independence of Namibia on 21 March 1990 and elections which saw SWAPO win 55 of 72 seats in the National Assembly of Namibia, enabling them to form a national government (MTEF 2008; RoN 2008; AfDB 2009).

It is a young country with a modernizing infrastructure. Namibia celebrated its $22^{\text {nd }}$ independence day in 2012. The tertiary sector in Namibia contributes more than 50 per cent to GDP, followed by primary and secondary industries. Mining and quarrying account for about 13 per cent of GDP, compared with 6 per cent and 4 per cent for agriculture and fisheries, respectively (Rena 2010). Tourism is the third largest foreign exchange earner after diamond and fish exports. Namibia has a highly developed banking sector with modern infrastructure, such as online banking and cell-phone banking among others. The Bank of Namibia (BoN) is the central bank of Namibia and is responsible for functions performed by a central bank. There are four BoN authorised commercial banks in Namibia: Bank Windhoek, First National Bank, Nedbank and Standard Bank (RoN 2001).

Namibia is linked to several African countries. It is a member of the Common Monetary Area, together with Lesotho, South Africa and Swaziland, and the Namibian dollar is pegged to the South African rand on a one-to-one basis. The countries have their own central banks and monetary policies, as reflected in differing interest rates. However, Namibia's economy is closely linked to the South African economy due to South African subsidiaries being involved in Namibian sectors such as wholesale, retail and 
financial. In addition, Namibia sources about 80 per cent of imports from or through South Africa, while about 30 percent of exports are destined for South Africa. Namibia is thus exposed to imported inflation from South Africa (Rena 2010).

The country has a high unemployment rate. "Strict unemployment" (people actively seeking a full-time job) stood at $20.2 \%$ in 2000, $21.9 \%$ in 2004 and spiraled to $29.4 \%$ in 2008 . Under a broader definition (including people that have given up searching for employment) unemployment rose from $36.7 \%$ in 2004 to $51.2 \%$ in 2008 (RoN 2010). This estimate considers people in the informal economy as employed. Approximately half the population live below the international poverty line of USD1.25 a day. There are a number of legislative measures in place to alleviate poverty and unemployment. In 2004, a labour act was passed to protect people from job discrimination stemming from pregnancy and HIV/AIDS status (CIA 2009; UNAIDS 2010; Rena 2010).

Agriculture and incidence of poverty are linked. Although agriculture contributes only about 6 per cent to GDP, it is an important sector in terms of employment opportunities. About half of the population depends on agriculture for its livelihood, but Namibia must still import more than 50 per cent of its food and 80 per cent of consumer goods particularly from South Africa (Werner 2001; Rena 2010). Although per capita GDP is five times the per capita GDP of Africa's poorest countries, the majority of Namibia's people live in rural areas and exist on a subsistence way of life. Namibia has the highest rates of income inequality in the world (Gini coefficient rate 70.7), due in part to the fact that there is an urban economy and a rural cash-less economy (CIA 2009). About 4,000, mostly white, commercial farmers own almost half of Namibia's arable land. The governments of Germany and Britain intend to finance Namibia's land reform process, as Namibia plans to start expropriating land from white farmers to resettle landless Black Namibians in the near future.

The economy is undergoing transformation. Agreement has been reached on the privatisation of several more enterprises in coming years, with hopes that this will stimulate much needed foreign direct investment. However, reinvestment of environmentally derived capital has hobbled Namibian per capita income $\$ 5,828$. One of the fastest growing areas of economic development in Namibia is the growth of wildlife conservancies. These conservancies are particularly important to the rural generally unemployed population. For example, an aquifer called "Ohangwena II" has been discovered, capable of supplying the 800,000 people in the North for 400 years (McGrath 2012). Experts estimate that Namibia has $7720 \mathrm{~km}^{3}$ of underground water).

Culturally, the country is diverse. The majority of the Namibian population is of Bantu-speaking origin - mostly of the Ovambo ethnicity, which forms about half of the population. They reside mainly in the north of the country, although many are now resident in towns throughout Namibia. Other ethnic groups are the Herero and Himba people who speak a similar language. The Damara speak the same "click" language as the Nama. In addition to the Bantu majority, there are large groups of Khoisan (such as Nama and Bushmen), who are descendants of the original inhabitants of Southern Africa. The country also contains some descendants of refugees from Angola. There are also two smaller groups of people with mixed racial origins, called "Coloureds" and "Basters" $6.6 \%$ (with the Coloureds outnumbering the Basters two to one). There is a large Chinese minority in Namibia (RoN 1990; Kössler and Melber 2001; Malia 2008).

\section{Foreign Presence is Significant}

Whites of Portuguese, Dutch, German, British and French ancestry make up about $6.4 \%$ of the population; they form the second-largest population of European ancestry, both in terms of percentage and actual numbers, in Sub-Saharan Africa after South Africa (CIA 2009). Most Namibian whites and nearly all those of mixed race speak Afrikaans and share similar origins, culture, and religion as the white and coloured populations of South Africa. A smaller proportion of Whites (around 30,000) traces their family origins directly back to German colonial settlers and maintain German cultural and educational institutions in the country. Nearly all Portuguese settlers came to the country from the former Portuguese colony of Angola (The Economist 1975). The 1960 census reported 526,004 persons in the South West Africa, including 73,464 Whites (14 per cent) (Singh 1980). 
Namibia is a country in transition. Namibia is classified as 'upper middle income' country, with a gross domestic product (GDP) per capita of over $\$ 5,800$. Namibia shares many developmental challenges with countries in the region: poverty; natural disasters such as floods and drought; the HIV/AIDS epidemic; concerns for quality education; and exposure to globalization, as well as rising food and fuel prices. Its unemployment rate is 22 per cent and poverty rate is 28 per cent.

Socio-political challenges exist. Since its independence, the Namibian government has implemented and maintained a liberal economic policy regime, emphasising incentives for investments and a stable macroeconomic environment; it has also taken a rather cautious approach to the issue of redistribution of land, assets and capital. Namibia has maintained political stability and succeeded in reducing its levels of inflation, with the result that the country has become integrated in the world economy and foreign investments and tourism have expanded. At the same time, the public sector has expanded rapidly since independence and a large share of public expenditures has been redirected to primary health care and education. Namibia has a large public sector, and tax revenues finance the central government as well as regional and local governments (MTEF 2008; RoN 2008; AfDB 2009). The central government employs 80,000 people, or around 5 per cent of the population. It has proved increasingly more difficult for the government to scale down public expenditures, as the growth-oriented policies have so far not yielded results in the form of substantial job creation. ${ }^{4}$ It may be argued that the government has attempted to address economic inequalities on the expenditure side of the budget, rather than on the revenue side (Rena 2010).

\section{Geopolitics in Namibia}

The Namibian landscape consists generally of five geographical areas, each with different characteristics with regard to climate, soil, water, geology, physiography and vegetation with some variation and overlap between them: the Central Plateau, the Namib Desert, the Great Escarpment, the Bushveld, and the Kalahari Desert.

The politics of Namibia takes place in a framework of a presidential representative democratic republic, whereby the president of Namib- ia is elected to a five-year term and is both the head of state and the head of government. Namibia is divided into 13 regions and subdivided into 107 constituencies. The administrative division of Namibia is tabled by Delimitation Commissions and accepted or declined by the National Assembly. Since state foundation, three Delimitation Commissions have been formed. Regional councillors are directly elected through secret ballots (regional elections) by the inhabitants of their constituencies. The Constitution of Namibia guarantees the separation of powers (RoN1990).

Since independence, Namibia has successfully completed the transition from white minority apartheid rule to parliamentary democracy. Multiparty democracy was introduced and has been maintained, with local, regional and national elections held regularly. Several registered political parties are active and represented in the National Assembly, although Swapo Party has won every election since independence. The transition from the 15-year rule of President Sam Nujoma to his successor, Hifikepunye Pohamba in 2005 went smoothly and he was re-elected for the second term in 2010.

Namibian government has promoted a policy of national reconciliation and issued an amnesty for those who had fought on either side during the liberation war. The civil war in Angola had a limited impact on Namibians living in the north of the country. In 1998, Namibia Defence Force (NDF) troops were sent to the Democratic Republic of the Congo as part of a Southern African Development Community (SADC) contingent. In August 1999, a secessionist attempt in the Northeastern Caprivi region was successfully quashed.

\section{Education and Health}

The educational system in Namibia is developing. The country has compulsory free education for 10 years between the ages of 6 and 16 . Grades 1-7 are primary level, grades 8-12 secondary. In 1998, there were 400,325 Namibian students in primary school and 115,237 students in secondary schools. The pupil-teacher ratio in 1999 was estimated at 32:1, with about $8 \%$ of the GDP being spent on education. Curriculum development, educational research, and professional development of teachers is centrally organised by the National Institute for Educational 
Development (NIED) in Okahandja. Most schools in Namibia are state-run, but a few private schools are also part of the country's education system. There are four teacher training colleges, three colleges of agriculture, a police training college, a Polytechnic at university level, and a National University (World Bank 2005).

AIDS pose a serious health and productivity problem. Life expectancy at birth is estimated to be 52.2 years in 2012 - among the lowest in the world. The AIDS epidemic is a large problem in Namibia. Though its rate of infection is substantially lower than that of its Eastern neighbor, Botswana, approximately $13.1 \%$ of the adult population is infected with HIV. In 2001, there were an estimated 210,000 people living with HIV/ AIDS, and the estimated death toll in 2003 was 16,000 . According to the 2011 UNAIDS Report, the epidemic in Namibia "appears to be leveling off." As the HIV/AIDS epidemic has reduced the working age population, the number of orphans has increased. It falls to the government to provide education, food, shelter and clothing for these orphans (UNAIDS 2011).

Other health concerns are emerging. The malaria problem seems to be compounded by the AIDS epidemic. Research has shown that in Namibia the risk of contracting malaria is $14.5 \%$ greater if a person is also infected with HIV. The risk of death from malaria is also raised by approximately $50 \%$ with a concurrent HIV infection. Given infection rates this large, as well as a looming malaria problem, it may be very difficult for the government to deal with both the medical and economic impacts of this epidemic. The country had only 598 physicians in 2002 (UNAIDS 2010).

\section{Tourism and Wildlife}

Tourism is a major contributor (14.5\%) to Namibia's GDP, creating tens of thousands of jobs (18.2\% of all employment) directly or indirectly and servicing over a million tourists per annum (Hartman 2009). The country is among the prime destinations in Africa and is known for ecotourism which features Namibia's extensive wildlife.

There are many lodges and reserves to accommodate eco-tourists. Sport Hunting is also a large and growing component of the Namibian economy, accounting for $14 \%$ of total tourism in the year 2000, or \$ 19.6 million, with Namibia boasting numerous species sought after by international sport hunters (RoN 2001; Humavin$\mathrm{du}$ and Jonothan 2003). In addition, extreme sports such as sand boarding and rough terrain driving have become popular. Several travel companies provide tours The most visited places include the Caprivi Strip, Fish River Canyon, Sossusvlei, the Skeleton Coast Park, Sesriem, Etosha Pan and the coastal towns of Swakopmund, Walvis Bay and Lüderitz.

Namibia is one of few countries in the world to specifically address conservation and protection of natural resources in its constitution. Article 95 states, "The State shall actively promote and maintain the welfare of the people by adopting international policies aimed at the following: maintenance of ecosystems, essential ecological processes, and biological diversity of Namibia, and utilization of living natural resources on a sustainable basis for the benefit of all Namibians, both present and future (RoN 1990)."

In 1993, the newly formed government of Namibia received funding from the United States Agency for International Development (USAID) through its Living in a Finite Environment (LIFE) Project. The Ministry of Environment and Tourism with the financial support from organizations such as USAID, Endangered Wildlife Trust, WWF, and Canadian Ambassador's Fund, together form a Community Based Natural Resource Management (CBNRM) support structure. The main goal of this project is promote sustainable natural resource management by giving local communities rights to wildlife management and tourism (CIA 2009).

\section{Key Challenges and Opportunities}

\section{Poverty}

The government's second progress report on achieving the Millennium Development Goals (MDGs) was released in 2009. The gender-related targets are on schedule but progress on health is seriously lagging. As stated earlier that Namibia has the highest economic disparity in the world. In 2008 Namibia introduced the Cost of Basic Needs (CBN) approach to measure poverty. Households were defined as poor and severely poor if adult consumption levels were below NAD 265.24 and NAD 184.56 respectively. Poverty used to be defined by the food consump- 
tion ratio: people who spent 60 per cent or more of total consumption on food were considered poor, while people who spent more than 80 per cent on food were considered severely poor.

According to the food consumption ratio measures, the percentage of poor people has declined from 38 per cent in 1994 to 28 per cent in 2004, while the proportion of severely poor people has gone down from 9 per cent to 4 per cent. According to the CBN approach poverty stands at about 28 percent, while the proportion of severely poor households is 14 percent. Poverty levels are highest among female-headed households in rural areas with one or more children. Child poverty in Namibia is rife. Approximately one in five children under the age of five is severely malnourished. However, the number of malnourished children has declined from about 28 per cent to 24 per cent. Namibia is unlikely to eradicate extreme poverty and hunger by 2015 (MTEF 2008; RoN 2008; AfDB 2009).

\section{Education and Gender}

The Namibian government realized that education is corner stone of economic and social advancement (Rena and Kidane 2009). The government invested 25 percent of its budget in 2008/ 09 on education, which is considered a priority. Primary enrolment rates and youth literacy rates remain at 83.8 percent and 92.7 percent respectively. The level of education among learners and teachers was considerably lower than in neighbouring countries. Dropout and repetition rates are high. 94 per cent of pupils make it to fifth grade while 81 percent reach eighth grade. Regional disparities in survival and literacy rates as well as school facilities are huge. Namibia has made some progress towards achieving universal primary education. About 87.4 percent of females are literate as opposed to 88.6 per cent of males. In primary education, there are 98 females per 100 males, in secondary education there are 117 females per 100 males, while in tertiary education there are 88 females per 100 males. School children continue to perform poorly and drop out and repetition rates remain high. Although the number of people infected with HIV has dropped slightly from 19.9 percent to 17.8 per cent and treatment is improving, it remains a major concern. Nonetheless, women are underrepresented in professional jobs and in higher level positions. Gender-based violence and dis- crimination are significant hindrances to women's empowerment. HIV/AIDS are a major obstacle to development in Namibia. An estimated 200000 people -60 percent of whom are women - are living with HIV. The HIV prevalence rate among pregnant women fell from 19.9 percent in 2006 to 17.8 per cent in 2008 (UNAIDS 2010).

According to national sources, the infection has reduced life expectancy significantly from 61 years in 1991 to 43 years in 2000 and left about 66000 children orphaned. The proportion of advanced HIV sufferers with access to anti-retroviral treatment (ART) rose from 3 per cent in 2003 to 66 per cent in 2006, increasing the number of people living with HIV. In 2009, the national budget financed the treatment of 65000 infected people. Although the child mortality rate for children below the age of five had fallen over the past decade, HIV/AIDS might now change this. Between 2000 and 2008, infant and child mortality rates have decreased from 37 to 34.4 and 62 to 50 respectively per 1,000 live births. Immunisation against preventable diseases has also improved. Eighty four per cent of one-year old children are immunised against measles while 70 per cent of children are immunised against all preventable diseases. Conversely, maternal mortality has increased from 271 in 2000 to 449 in 2006 per 100000 births. This is largely due to HIV/AIDS and despite an increase in the number of medical staff during births. Since Namibia is a large and sparsely populated country, distance and very few rural medical staff prevent people from receiving medical care in time. Achieving the MDGs for child mortality and maternal health by 2015 remains a challenge (MTEF 2008; RoN 2008; AfDB 2009; Rena 2010; UNAIDS 2010).

Tuberculosis (TB) cases decreased from 822 per 100,000 in 2004 to 205 in 2007. Simultaneously the success rate of TB treatments rose from 70 percent to 76 percent. Malaria incidences fell from 238 in 2000 to 48 per 100,000 in 2007. In Namibia, malaria is a seasonal infection, which mainly affects the northern parts of the country where roughly 60 percent of the population lives. Unemployment remains high at 21.9 per cent while there is a shortage of skilled labour. Most unemployed people have only completed secondary education. The labour market mismatch is also manifested in large wage differentials between skilled and unskilled workers (RoN 2010). 
The 2008/09 Global Competitiveness Report identified that restrictive labour regulations, poor work ethics, and a lack of skills had prevented competitiveness in Namibia. Furthermore, the capital intensity of the growing mining sector and a decline in agricultural labour contributed to unemployment. The new labour act prohibits temporary employment agencies and transient workers.

In Namibia, food prices rose in May 2008 by 16.5 per cent compared to prices in May 2007, and by 40 per cent compared to May 2005. The driving forces of the current price spike of staple and other food products can largely be found in the regional and global context. However, food prices in Namibia increased less than in other countries due to a conservative pricing agreement between producers and millers. Roughly 1.5 million of Namibia's total population of about 2 million depend on subsistence farming for their household food security (Werner 2001; Rena 2010). While they are vulnerable to changing climate conditions the other part of the population, especially poor urban dwellers, are more vulnerable to food price increases. As a member of the Southern African Customs Union (SACU), Namibia has surrendered its sovereignty over trade policy to a large extent to SACU. Namibia is also a member of the Southern African Development Community (SADC) Free Trade Agreement. Namibia has initialled an Interim Economic Partnership Agreement that allows duty-free and quota-free access to the European Union (EU) market. Namibia is a founding member of the World Trade Organization (WTO) and has been declared a net food importing developing country (NFIDC), a designation that will provide Namibia with more policy space in order to increase national food production (Kameri 2000; The AfDB/OECD 2009).

The agricultural sector's performance is strongly dependent on weather conditions; hence food self-sufficiency varies between 35 percent and 75 percent of total demand. The government has implemented and continues to implement a set of measures to counteract the effects of climate change and rising food prices on the national food security situation of Namibia. Some of these are the usage of natural water courses for irrigation farming, the construction of national storage capacity for staple grains, increased long-term production through title deeds and targeted extensions, and targeted food assistance. Furthermore, the government is controlling the import of staple food and horticultural products in order to increase food security and exploit Namibia's agricultural production potential.

The Namibian Constitution allows foreigners to own businesses in Namibia, Part VI of the Agricultural (Commercial) Land Reform Act, 1995 (No. 6 of 1995) places heavy restrictions on foreign ownership of commercial farmland. However, foreigners can buy commercial farmland in Namibia, this would add to demand and push land prices up (Sherbourne 2000).

\section{Water Problem}

For Namibia's capital city, the goal of sustainable water and sanitation is a major challenge for the 21st century. Windhoek had just 140,000 inhabitants at independence in 1990. In 20 years, the population has more than doubled to 300,000 people, according to the city government, with between 20 and 30 percent living in informal settlements. These unplanned areas have grown at a rate of 9.4 percent each year, making the provision of water and sanitation a serious challenge (Munetsi 2011).

As discussed in this paper that Namibia's geopolitical environment is complex and has been facing numerous challenges. Nonetheless, it has potential opportunities for business development. For example, the tertiary sector contributes more than 50 percent to GDP, followed by primary and secondary industries. Mining and quarrying account for about 13 percent of GDP, compared with 6 percent and 4 percent for agriculture and fisheries, respectively. As discussed earlier that the tourism is the third largest foreign exchange earner after diamond and fish exports. Although agriculture contributes only about 6 percent to GDP, it is an important sector in terms of employment opportunities. Furthermore, agriculture provides the inputs for the manufacturing sector, in particular meat and food processing, hence adding further to employment creation. The annual national budget allocates on average 7 percent to agriculture and agricultural development. This is below the 10 percent agreed in the Dar es Salaam Declaration of the SADC Heads of State. Nevertheless, agriculture and agricultural development comprise one of the key policies of the Government of Namibia. Namibia's economic policy is based on 
the long-term Vision 2030, implemented through medium-term National Development Plans (De Villiers 2003; RoN 2008). The Third National Development Plan covers the period 2007-12, and aims, among other things, to enhance agricultural production both at the household and national levels in order to increase food security and create employment opportunities (Sherbourne 2000). One of the main goals is to utilize the soil in an optimal and sustainable manner in order to enhance crop and horticulture production.

Another goal is to promote sustainable livestock production through the optimal and sustainable utilization of rangeland. It is the national objective to achieve national food security, not food self-sufficiency. Therefore, government has embarked on initiatives to increase food security, such as the construction of silos in the communal areas and the finalization of the Green Scheme Policy and land reform, which are improving crop and horticultural production in the country (Werener 2001; Rena 2010).

Further, in terms of access to food, after two major international price spikes in 2007-08 and 2010-11, populations in nearly 60 developing countries are paying 80 per cent more, on average, for local foodstuffs in 2012 compared to pre-crisis price levels. This also had a dramatic impact on Namibia. In line with this there is a potential to develop the renewable energy base in the country.

\section{Oil and Natural Gas in Namibia}

As stated earlier, Namibia has firm macroeconomic policies, efficient political structures, growing financial institutions, and its corruption index is also much better if put in comparison with other African countries. Namibia's currency is also directly linked to the South African Rand and is therefore not as much affected by currency fluctuations. Recently the Namibian Mines and Energy Minister, Isak Katali, announced the discovery of vast oil reserves off the Southern Namibian coast. This discovery has created huge expectations in Namibia, and many hope that the revenue collected from oil production would relieve poverty and jump start the development in the country. The question that needs to be asked is whether Namibia has the capacity to properly manage this and whether this oil base will have any advantages for the
Southern African region? This in other hand provides a potential to the global community that can invest enormously in the business development.

To put the find in perspective, it is estimated to hold 11 billion barrels, which is nearly equal to that of Angola's reserves of 13 billion barrels of oil, according to the weekly Namibian Economist. Angola recently surpassed Nigeria as Africa's top producer of oil and is expected to surpass even Kuwait's oil production in the near future. It would make Namibia Africa's 5th largest producer of oil after Libya, Nigeria, Algeria, and Angola.

Paradoxically, in most cases, production of oil has brought little benefit to ordinary Africans. Economists call this the "resource curse" - economies becoming over reliant on an extractive commodity such as oil. In such an economy exchange rates tend to appreciate which in turn makes imports cheaper to the point where it undermines local production and industrial development. In Angola for example oil production accounts for about 85 per cent of its GDP, 90 per cent of its export revenue, and nearly two thirds of government revenue.

The biggest winner from this oil discovery would be Namibia. If correctly managed, the country will have the opportunity to make large investments into health, education, and social welfare. Regionally, South Africa stands to benefit the most. By importing oil directly from Namibia, South Africa could limit the impact of price fluctuations on the international oil market, and could in theory become more independent from organizations such as OPEC. This would however entail South Africa and Namibia undertaking bi-lateral agreements with one another concerning the issue.

South Africa is also the regions refining powerhouse. South Africa has close to 80 per cent of refining capacity within Southern Africa and has provided the majority of refined products for Namibia for years now. Recently, according to research and consultancy firm Frost \& Sullivan, Namibia decreased its reliance on South Africa for a 100 per cent of their refined product to 50 percent in order to ensure that it's not dependant on only one country for its petroleum products. Namibia still doesn't have the technical knowledge to do their refining on their own however and South African companies could still take advantage in refining Namibian oil. 
The issue does have some security implications for the region as well. Namibian oil discoveries would have to be protected, and Namibia does not have any efficient naval or maritime policing capability to do so. Currently South Africa is the only credible naval power in the region and it could be expected that Namibia would ask South Africa for some assistance in this regard until Namibia builds up its own maritime capabilities.

Extra care would also have to be taken by Namibian authorities to ensure environmental protection. Any form of pollution or maritime disaster so close to the South African border would not only impact Namibia negatively but would surely have an impact on South Africa as well. Namibia does however maintain an excellent environmental record to ensure the protection of its own tourism industry.

The Namibian government would have to ensure that proper controls are in place before the start of oil production by 2016. If the process is not properly managed Namibia could suffer the same oil induced tragedies that other African countries have experienced in the past such as severe income inequalities, entrenched poverty, and environmental degradation. ${ }^{5}$

\section{Labour Market and Investment}

Regarding labour markets across Namibia, they are characterized by fewer, lower-paying jobs and proliferating the incidence of working poverty that had already trapped nearly half of the population/ productive labourers currently unable to find a job. Further, rampant youth unemployment coupled with a quickly expanding supply of young labourers-more than one million are expected to enter the Namibia's labour market between 2012 and 2020 - are only adding to on-going labour market woes in the country. Government of Namibia is also pursuing business development strategies that could lead to heightened infrastructure development and which would eventually support the expansion of economic activities that could provide an impetus for the investors to invest substantially in the business sector.

Importantly the simultaneous effects of inflation, low income base and service delivery shocks have potentially severe and irreversible consequences, especially the rural and urban poor. Among these include increased hunger and malnutrition, HIV/AIDs worsening health outcomes, lower school attendance, higher rates of child labour and domestic violence, rising vulnerability to future shocks and widespread social unrest which may attract some international NGOs to ameliorate the current socio-economic situation of the vulnerable communities in the country.

However, this current situation of Namibia may also present an opportunity to rethink Namibia's socio-economic policies for development. This requires shedding the myopic scope of macroeconomic and fiscal policy decisions of the past and, instead, basing them on their potential to achieve food security, full employment, human development, and inclusive and sustainable growth.

In line with this, Namibian government may consider in adopting and implementing the six broader development principles, which are supported by policy statements of the United Nations. These include: re-allocating public expenditures; increasing tax revenues; lobbying for increased aid and transfers; tapping into fiscal and foreign exchange reserves; borrowing and restructuring existing debt; and/or adopting a more accommodative macroeconomic framework.

To do so, social and economic investments must be prioritized within a flexible, longer-term framework, recognizing that there are a variety of financing options available to bolster these much needed investments in Namibia in the context of the changing geopolitical climate of the world.

\section{CONCLUSION}

This article discusses the geopolitical environment in Namibia and provides a comprehensive picture of the country's, economy, polity, education and health situation in the country. It also highlights the environment and migration issues in general and how that affect a developing country like Namibia. It further argues that action is required by a broad group of policy makers, and not just those concerned with the environment or migration. Typically 'migration' policy in Namibia falls within the remit of Ministry of Home Affairs, which is responsible for 'managing' international flows of people, while environment and climate change is the remit of Ministry of Environment and Tourism in Namibia. Besides, on this issue, the Ministry of Agri- 
culture, Water and Rural Development is also one the important stakeholders to consult with. However, the interactions between environmental change and migration demand, agriculture and rural development attention from a far broader spectrum of actors as the issue affects adaptation funding, development cooperation, urban planning, rural affairs, conflict management and disaster planning as well as migration and environmental policy. Action and coordination will also be required between different tiers of policy makers. The business development implications of the policy options discussed in this article are relevant to local authorities (including district and city governments), national governments in Namibia and around the world, and various international and inter-governmental organisations.

\section{NOTES}

1. http://www.prb.org/Educators/TeachersGuides/HumanPopulation/Environment.aspx accessed on 27 October 2012.

2. See for more details http://www.prb.org/Educators/ TeachersGuides/HumanPopulation/Environment. aspx accessed on 27 October 2012.

3. The Basters (also known as Baasters, Rehobothers or Rehoboth Basters) are the descendants of Cape Colony Dutch and indigenous African women. They live largely in Namibia and are similar to Coloured or Griqua people in South Africa. The name Baster is derived from the Dutch word for "bastard" (or "crossbreed")

4. The decision taken by the SWAPO government in 1998 to absorb 9000 ex-combatants into the civil service, The Peace Project, underscores how the SWAPO government sees its role in employment creation.

5. http://onesocietyinitiative.org/implications-ofnamibias-oil-find-212 (published on 03 August 2011) accessed on 29 October 2012.

\section{REFERENCES}

African Development Bank / Organization of Economic Cooperation and Development 2009. Namibian Chapter: African Economic Outlook 2009. From <http://www.nepru.org.na/fileadmin/E Resources_Library/Africa_Economic_Outlook/ 2009/Namibian_Chapter.pdf $>$ (Retrieved on September 18, 2012).

Central Intelligence Agency 2009. Namibia: The World Factbook (Retrieved January 23, 2010).

De Villiers B 2003. Land Reform: Issues and Challenges. A Comparative Overview of Experiences in Zimbabwe, Namibia, South Africa and Australia. Johannesburg: Konrad- Adenauer-Stiftung.

Evans G, Newnham J 1998. The Penguin Dictionary of International Relations. London: Penguin Books.
Hartman A 2009. Tourism in Good Shape - Minister. The Namibian. From <http://www.namibiatourism. com.na/namibia-top-attractions/ (30 September) Namibia top tourist destinations> (Retrieved on September 29, 2012).

Humavindu MN, Barnes JI 2003. Trophy hunting in the Namibian economy: An assessment. South African Journal of Wildlife Research, 33(2): 65-70.

Joint United Nations Programme on HIV/AIDS (UNAIDS) 2010. Report on the Global AIDS Epidemic 2010. Geneva, Switzerland: UNAIDS.

Kameri SD 2000. Approaches and Strategies on Improving and Strengthening Development Co-operation and Debt-management in Namibia. Draft Report to the National Planning Commission.

Kössler R, Melber H 2001. Political culture and civil society: On the state of the Namibian State. In: I Diener, O Graefe (Eds.): Contemporary Namibia: The First Landmarks of a Post-apartheid Society. Windhoek: Gamsberg Macmillan, pp. 147-160.

McGrath M 2012. Vast Aquifer Found in Namibia Could Last for Centuries. BBC World Service, 20 July 2012. (Retrieved on October 28, 2012).

Medium Term Expenditure Framework (MTEF) 2008. Development Programmes: Medium term Expenditure Framework 2008/2009 to 2010/2011. Windhoek: Government of Namibia.

Munetsi R 2011. Global Geopolitics and Political Economy. From <http://globalgeopolitics.net/wordpress/ 2011/03/11/namibia-water-in-the-kambashu/> (Retrieved on October10, 2012).

NEPRU 1999. The Namibian Economy: A NEPRU Viewpoint No.22. Namibia: Windhoek.

NPC 2012. Census Summary Results. National Planning Commission of Namibia. From <http://www. npc.gov.na/census/index.htm> (Retrieved on September 21, 2012).

Oyvind O 1988. The uses and abuses of geopolitics. Journal of Peace Research, 25 (2): 191-199.

Politzer M 2008. China and Africa: Stronger economic ties mean more migration. Migration Information Source (August)

Rena Ravinder, Kidane E 2009. Eritrean Educational Reforms-Issues, Perspectives and Policy Implications. Hyderabad, (India): The ICFAI University Press, P. 285.

Rena Ravinder 2010. Namibian economy: Recent developments and future expectations. Journal of Social and Economic Policy, 7(1): 129-142.

RoN/Republic of Namibia 1990. Constitution of the Republic of Namibia. Windhoek: Ministry of Information and Broadcasting, Government of the Republic of Namibia.

RoN/Republic of Namibia. 2001. The Namibia Labour Force Survey 1997: Final Report of Analysis. Windhoek: Republic of Namibia.

RoN/Republic of Namibia 2008. Third National Development Plan (NDP3) 2007/2008 -2011/12. Volume, Windhoek, Government of Namibia.

RoN/Republic of Namibia. 2010. The Namibia Labour Force Survey 2008: Final Report of Analysis. Windhoek: Republic of Namibia.

Sherbourne R 2000. "Couldn't happen here?" Growth Namibia, 1: 19-21.

Singh LP 1980. The United Nations and Namibia. Nairobi (Kenya): East African Publishing House. 
The Economist 1975. Flight from Angola. 16 August, 1975. From <http://www.economist.com/node/ 12079340 ?story_id=12079340> (Retrieved on October 23, 2012).

UNAIDS 2010. Report on the Global AIDS Epidemic 2011. Geneva, Switzerland: UNAIDS

UNDP 2009. Human Development Report-2009. Geneva: UNDP

United Nations 2008. Department of Economic and Social Affairs Population Division (2009). World Population Prospects, Table A.1. 2008 revision.
2009. From <http://www.un.org/esa/population/ publications/wpp2008/wpp2008_text_tables.pdf> (Retrieved on October 12, 2012).

Werner W 2001. The land question in Namibia. In: I Diener, O Graefe (Eds.): Contemporary Namibia: The First Landmarks of a Post-apartheid Society. Windhoek: Gamsberg Macmillan, pp. 259-272.

World Bank 2005. Namibia Human Capital and Knowledge Development for Economic Growth with Equity. Human Development Sector, Africa Region, Working Paper Series No. 84. Washington, DC: World Bank. 